\title{
Murburn model of mitochondrial aerobic respiration is robust in comparison to the 'chemiosmotic rotary or two-ion torsional' ATP-synthesis proposals
}

A letter to the editor, in response to two recent articles published in Biophysical Chemistry (2020): [1] "Chemiosmotic misunderstandings" by Pedro J. Silva \& [2] "Molecular-level understanding of biological energy coupling and transduction" by Sunil Nath.

\section{Daniel Andrew Gideon*}

Assistant Professor, Department of Biotechnology and Bioinformatics,

Bishop Heber College (Autonomous),

Vayalur Road, Tiruchirappalli, Tamil Nadu, India-620017.

*corresponding author's email: dnlndrwster@gmail.com

One of the most fundamental questions in biology pertains to how mechano-chemical energy is derived from metabolic fuels. In particular, how oxidation of NADH is linked to ATP synthesis in mitochondrial oxidative phosphorylation (mOxPhos) has been a topic of intense debate. Together, the Peter Mitchell-Paul Boyer proposals for mOxPhos are termed herein as "chemiosmotic rotary ATP synthesis" (or CRAS) model, which was recently defended/advocated by Pedro Silva in Biophysical Chemistry [1, and the relevant citations therein]. Over the last two decades, Sunil Nath had questioned some aspects of the CRAS proposal, and made subtle alterations on the roles of Complex $\mathrm{V}$ and ions within the reaction scheme, and continues to advocate his framework as "two-ion torsional ATP synthesis" (abbreviated herein as TITAS) model in Biophysical Chemistry [2, and the relevant citations therein]. Kelath Murali Manoj had revisited the data on the respiratory machinery's structures/distributions and based on two-decades of evidence-based experimental research in redox enzymology of heme/flavin proteins, had formulated the murburn model for mOxPhos. He had recently pointed out the flaws and physiological non-viability of the CRAS-TITAS proposals within a brief letter to the Editor of Biophysical Chemistry [3]. Some aspects of Manoj's group's works/ideas were subsequently rebutted and critiqued by Silva [1] and Nath [2, and an earlier publication cited therein]. Further, the publication process of Biophysical Chemistry did not permit Manoj the opportunity to respond to the arguments traded by the adherents of CRAS-TITAS on the journal's platform [4-5]. When I read the pertinent communications [1-5, and the relevant publications cited therein], it was quite evident to me that the advocates of CRAS-TITAS had resorted to false attributions and patronization in their attempt to pull down Manoj's writings and disowned facts while defending their own stances. This scenario continues unabated, perhaps owing to the complications/magnitude of the problem and also due to conflict of interests at various quarters. As a long-standing 
collaborator of Prof. Manoj, I bear testimony to the fact that several unusual experimental observations in porphyrin-flavin-FeS proteins mediated redox enzymology can only be explained by murburn concept, which advocates that DROS (diffusible reactive oxygen species) could also serve as physiological agents of catalysis [6-32]. The importance of the new murburn paradigm [13] is manifest in its ability to better explain metabolic and physiological phenomena like- anomalous redox enzyme kinetics [6,7], inter-protein electron transfers [8,23,24,30], drug/xenobiotic metabolism [7-10,31], unusual dose responses [6,15], aerobic respiration and its evolution [11-14,16-23], thermogenesis [11,14,18,20], homeostasis [20,32], photoreception [29] and oxygenic photosynthesis [23-29], etc. In the current context, the murburn model reasons why earlier mOxPhos researchers failed to isolate any enzymelinked high-energy intermediate like 'phosphohistidine' (the original proposal from Boyer) [33]. My students are aware of the murburn model of mOxPhos and have come to understand and concur with Manoj's criticism of the CRAS model. Yet, as a teaching faculty, I have to knowingly peddle the untenable concepts of the CRAS explanations to my students, who look at me with askance! Though stipulated by the university mandated syllabus, it is quite a burden to bear the guilt that stems from such a vain exercise. Therefore, in order to draw more attention to the matter and set things clearer, I offer a brief summation of the various aspects of the ongoing debate and the recent developments. This is done without going into the inconsequential intricacies, so that even graduate-level biologists/biochemists can understand the contextual overviews and underlying foundations, and avoid the obfuscations/pitfalls which are rampant in the field.

In the early 1960s, Peter Mitchell floated chemiosmosis proposal for mOxPhos, when not even a shred of experimental/theoretical evidence existed to support his ideas [19]. Though several seasoned researchers (to name a few: Britton Chance, Gilbert Ling, David Green, Robert Williams, Albert Lehninger, Gregorio Weber, Edward Slater, Walter Wainio, etc. $[5,19])$ vehemently opposed the idea, it gained traction and became popular within the next two decades. At this juncture, Boyer made a volte-face and floated Complex V mediated 'rotary ATP synthesis' (RAS; the first rotary function for any enzyme!), which gelled with Mitchell's ideas [34]. Though Mitchell and Boyer are no more and their original proposals have been altered significantly, the followers of CRAS continued to brave criticism and strengthen their hold on bioenergetics research. In his recent manuscript published in this journal, Nath critiqued Pedro Silva's defense of the CRAS proposal [1]; Silva had earlier maintained that "modification of a few of the initial details" of the chemiosmotic theory is 
"inconsequential" and researchers' scepticism arises due to misunderstandings [1]. But Nath is sure that Mitchell's erroneous assumptions destroy the chemiosmosis proposal and insinuates that Manoj misunderstands TITAS [2]; Silva reciprocates the same sentiments for Nath's derivations and ideas [1]. All can see that the original assumption for both models is based on proton/ion differentials across two phases: $\log _{10}\left\{\mathrm{H}^{+}\right\}_{\mathrm{L}} /\left\{\mathrm{H}^{+}\right\}_{\mathrm{R}}=p H_{R}-p H_{L}$; where $\mathrm{L}$ and $\mathrm{R}$ are positive and negative phases of inter-membrane space (IMS) and matrix, respectively. Thereafter, subtle differences in the two models' equations for unit ionic transport across membrane were derived as: Mitchell's (Silva's) driving force $=\left(\Delta \mu_{H}+\Delta \psi\right)$ \& Nath's driving force $=\left(\Delta \boldsymbol{\mu}_{\mathrm{H}}+\Delta \boldsymbol{\mu}_{\mathrm{A} / \mathrm{C}}\right)$. While Mitchell introduced an electrical term $(\boldsymbol{\psi})$ resulting from a chemical transport of protons, Nath introduces another term generated by the co-transport of a discrete ion $\left(\boldsymbol{\mu}_{\mathrm{A} / \mathrm{C}}\right)$, like dicarboxylates of Krebs cycle. That is, to "fix" the flawed CRAS model, Nath proposes that Complex V is a co-transporter (besides functioning as an ATPsynthase) of two ions: a proton as well as another ion or counter ion (which could be either anion or cation, subscripted as A/C in the TITAS equation above). In Boyer's 'splendid molecular machine' model of Complex V [34], it had to rotate with the inward movement of a few protons (via the $\mathrm{F}_{\mathrm{o}}$ module), while concomitantly binding ADP+Pi at the matrix side (of $F_{1}$ module). It had to achieve the $A D P+F_{1}$ binding overlooking the $10^{7}$ fold higher affinity for ATP (which is also available present in the matrix at much higher concentrations in steady state) [35]. Nath's Complex $\mathrm{V}$ has to achieve not only the improbable dictates of Boyer, but also must bind (and transport) organic anion at the IMS side (of $F_{o}$ module). This does not fix anything, but introduces even more insurmountable complications! More importantly, both CRAS and TITAS advocate the seemingly improbable premise that transport of ions across a membrane enables some conservation of energy, and that this energy is recycled to specifically give P-O bond formation at certain loci of Complex V (either via a rotary or torsional catalysis). That is, in both models, Complex V supposedly traps the driving force of a constant trans-membrane potential (TMP) using a 'circular' mechanism, with the very same chemical equation: ADP $+\mathrm{Pi} \rightarrow \mathrm{ATP}+$ Water. CRAS-TITAS fails to explain how a macroscopic TMP enables the endergonic bonding of two negatively charged phosphate moieties (ADP and Pi) at the $\beta$ subunits of Complex $\mathrm{V}$, without prior activation and without adequate energy reserves. Manoj had clearly pointed out that the matrix of a physiological mitochondrion has only $10^{0}$ to $10^{1}$ free protons $[11,12]$. Neither CRAS nor TITAS can obviate this predicament, as both have the $\Delta \boldsymbol{\mu}_{\mathbf{H}}$ term within the driving force equations. Ionic buffering cannot achieve the protonic/ionic gradients within the milieu and this has already been pointed out $[11,12]$. Further, mitochondrial dicarboxylic 
acids such as malate, succinate, fumarate, etc. have $\mathrm{pK}_{\mathrm{a}}$ values ranging from 3.0 to 5.5, two units below the physiological $\mathrm{pH}$. Considering that an average mitochondrion has $10^{4}$ to $10^{5}$ purported proton translocases (Complexes I through V) [12, based on 36,37], ushering in an equivalent amount of "dicarboxylate $+\mathrm{H}^{+}$" into the mitochondria would/must lower the mitochondrial $\mathrm{pH}$ to four units below the actually observed physiological value, which is not the case. As seen, in both CRAS and TITAS, one has to compromise with several known physiological realities and begin with multitudes of falsities. (Here, the false assumption made is: $10^{0}$ to $10^{1}=10^{4}$ to $10^{5}$ !! This is when the CRAS-TITAS purview was afforded the cushion of the minimal requirement of one protein $=1$ proton.) From the above analysis, it is evident that TITAS is a mere 'veiled' take-off on the original CRAS model, and hence, is akin to a "new patch on an old and torn garment". In contrast, Prof. Manoj has offered extensive critiques and alternative solutions on diverse aspects of prokaryotic/eukaryotic redox metabolic/bioenergetic routines that involve oxygen, like- xenobiotic metabolism [710,15,30,31], aerobic respiration [11-14,16-23,31] and oxygenic photosynthesis [23-29]. Based on the observations and explanations derived from the relatively simpler reductionist heme-flavin enzyme systems [6,9] and endoplasmic reticular membrane-embedded cytochrome P450 (CYP) drug metabolic array [7,8,10], his group's works have detailed how the more complex mOxPhos routine could be better understood $[11,18]$. There is no context for invoking TMP as an explicatory rationale within the CYP system. As a consequence, the similarities between CYP and mOxPhos systems, like- heme-centered activation of oxygen and generation of DROS, disconnection of 'electron transfer' from the productive reaction by membrane-embedded uncouplers like dinitrophenol, non-integral and variable stoichiometry, etc. [11]- must invoke an alternative rationale. The DROS-based murburn explanations accounted for the cross-system similarities $[4,13]$ and superseded the classical explanations in the CYP system with as many as 50 distinct theoretical/experimental points [10]. Such monumental developments merit the discard of TMP-based CRAS-TITAS explanation in mOxPhos. However, it is a pity that both drug metabolism researchers and bioenergetics scientists do not consider or cite these findings of utmost importance to biology/medicine, owing to conflict of interests.

In retrospect, although Mitchell was misplaced, he had original ideas and ruminated on the entirety of the mitochondrial system's components. To Nath's credit, he could figure out that Mitchell was wrong in adding the electrical term to make up for the energy shortage. But rather than getting to the crux of the problem (of determining oxygen's role in mOxPhos!), 
Nath "replaced the earlier Greek gods with his own Roman equivalents" (protons with anions+cations, 'proton-pump' with 'ions-translocase', 'rotary synthase' with 'torsional synthase', etc.). Further, Nath focuses almost always on the mechanism of Complex V, does not touch upon oxygen at all and mentions in the passing that other mitochondrial proteins serve to recycle the components (with terms- "symsequenceport" and "antisequenceport"), and adds more whorls to patch up the non-patchable and gaping falsities. Such TITAS treatments are not useful improvements on the misplaced CRAS model. I am a teacher who refers multiple reputed textbooks on biochemistry [35,38-41] and the TITAS proposal is cited in none of them. Therefore, to keep matters simple, henceforth, I shall focus only on the common facets of CRAS-TITAS proposals (Figure $1 \&$ Table 1 ) that are in vogue.

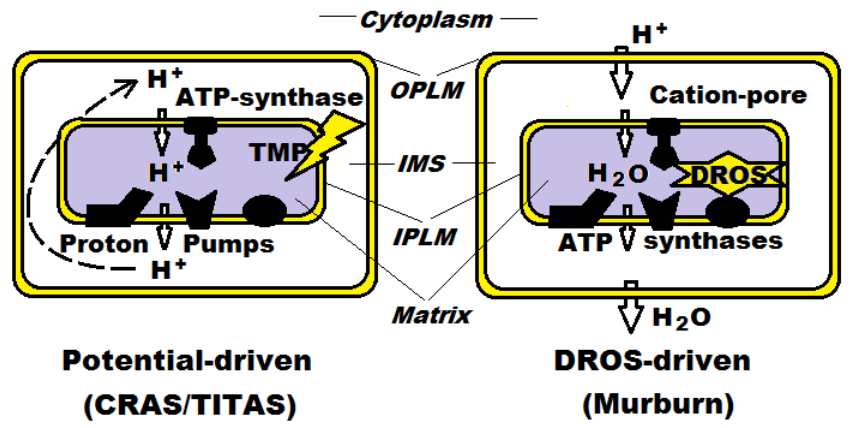

Figure 1. Comparison between CRAS/TITAS (left panel) vs. murburn model (right panel) of mOxPhos: OPLM and IPLM stand for outer and inner phospholipid membranes of mitochondria. Complexes I, III and IV (at the bottom) are proton pumps and electron transport chains in the CRAS-TITAS view whereas they are ADP-binding and DROS presenting murzymes within the murburn model. Protons/ions are translocated across the IPLM and recycled within a closed pot purview within CRAS-TITAS. In the murburn system, the cytoplasmic protons are required to produce water within mitochondria, whose formation and subsequent exodus leads to homeostasis. While the CRAS-TITAS seeks the impossible requisite that Complex $V$ (at the top) serves as a physiological ATP-synthase, the murburn model considers it a cation-pore and ATP-ase, serving as a chemostat for the reaction milieu in steady-state.

At the outset, I point out that both CRAS and TITAS models mistakenly presume that the physiologically observed TMP is what drives ATP synthesis in mitochondria. Murburn model explains that TMP is an outcome of the ATP-synthesis procedure of mOxPhos, quite akin to sound produced by a combustion engine [11]. Surely, it would be misplaced for anyone to argue that it is the sound that drives the engine which produces electricity/heat! Disregarding this misperception, both Silva and Nath keep focusing on the potential difference and forget that current is also an important factor in electrical power. When a synthetic rubber balloon is rubbed by hand, it generates several tens of thousands of volts of static electricity, but this process cannot give any decent workable force because of the miniscule and diffused stature of charge/ions involved. Similarly, the miniscule mitochondrial protonic efflux cannot explain the mOxPhos outcomes, as I have pointed out in the second paragraph within this 
discussion (and which Manoj had amply demonstrated through various calculations earlier $[11,12,18,19])$. Therefore, the feud between Silva and Nath stems from false-rooted assumptions. In sharp contrast with the unrealistic mandates of the CRAS-TITAS models that revolve around protons/ions and TMP, the murburn model offers a fresh and completely new chemical reaction perspective that centres on oxygen and DROS (Figure 1). Aerobic respiration's technical name is oxidative phosphorylation, isn't it? Does not oxygen deserve a greater role than what is currently ascribed to it by CRAS-TITAS? In this context, the oxygen-centric murburn model explains most known structural and physiological aspects of mitochondrial functioning [19], with totally different roles and functional correlations attributed to the components (Table 1). The arguments supporting my assertions are summarized in Figure 1 and Table 1, and the evidence for the same are discussed below.

Table 1: A comparison of the TMP-driven CRAS-TITAS and DROS-driven murburn models for mOxPhos.

\begin{tabular}{|c|c|c|c|}
\hline No. & Criterion & CRAS/TITAS & Murburn \\
\hline 1 & $\begin{array}{l}\text { Overview, } \\
\text { Equations and } \\
\text { Energetics }\end{array}$ & $\begin{array}{l}\text { Deterministic } 2 \text { e routes and stoichiometry; } \\
\text { electro-mechanical scheme; sequential and } \\
\text { multi-molecular reactions are kinetically } \\
\text { limited; irreducibly complex; harnessing } \\
\text { TMP to drive phospho-ester bond } \\
\text { formation; no chemical connectivity } \\
\text { between ATP-synthesis \& NADH oxidation; } \\
\text { does not address thermogenesis or } \\
\text { homeostasis; cannot explain the effects of } \\
\text { 'uncouplers' and cyanide. } \\
\text { (i) Succinate }+1 / 2 \mathrm{O}_{2}+\mathbf{8}_{\mathrm{i}} \mathrm{H}^{+} \rightarrow \text { Fumarate }+ \\
\mathrm{H}_{2} \mathrm{O}+\mathbf{8}_{\mathrm{o}} \mathrm{H}^{+} \\
\text {(ii) } \mathbf{2 A D P O H}+\mathbf{2 P O H} \rightarrow \mathbf{2 A D P O P}+\mathbf{2} \mathrm{H}_{2} \mathrm{O} \text { ( } \Delta \mathrm{G} \\
=+70 \mathrm{~kJ} / \mathrm{mol} \text { ) } \\
{ }^{\$} \mathrm{Available} \Delta \mathrm{G} \text { from Comp. III \& IV reactions } \\
=-(37+112 \text { ) } \mathrm{kJ} / \mathrm{mol} \\
{ }^{\#} \text { Expended } \Delta \mathrm{G} \text { to translocate one proton }= \\
+(79+20) \mathrm{kJ} / \mathrm{mol} \\
\text { Nett } \Delta \mathrm{G}=+643 \mathrm{~kJ} / \mathrm{mol} \text {; Unfavorable for } \\
\text { both complexes III \& IV; both (i) \& (ii) are } \\
\text { endergonic reactions and therefore, cannot } \\
\text { be chemically coupled! }\end{array}$ & $\begin{array}{l}\text { Stochastic } 1 \text { e route and variable cum } \\
\text { non-integral stoichiometry; chemical } \\
\text { scheme; unordered and bi-molecular } \\
\text { kinetically facile; evolutionarily facile; } \\
\text { harnessing radicals' reactivity for } \\
\text { phosphoanhydride formation in a } \\
\text { practically aprotic ambiance; direct } \\
\text { bimolecular chemical reaction } \\
\text { connectivity between ATP-synthesis \& } \\
\text { NADH oxidation; presents explanation } \\
\text { for thermogenesis and homeostasis; } \\
\text { explains 'uncoupling' and cyanide } \\
\text { toxicity as an outcome of DROS-proton } \\
\text { dynamics. } \\
\text { Succinate }+\mathbf{O}_{2}+2 \mathrm{ADPOH}+\mathbf{2 P O H} \rightarrow \\
\text { Fumarate }+2 \mathrm{ADPOP}+2 \mathrm{H}_{2} \mathrm{O}+\mathrm{H}_{2} \mathrm{O}_{2} \\
\Delta_{\mathrm{r}} G^{\prime O} \text { aq }=-39 \mathrm{~kJ} / \mathrm{mol}^{\prime} \text { [19] } \\
\text { The direct chemical reaction scheme is } \\
\text { thermodynamically viable for } \\
\text { explaining the overall physiological } \\
\text { observations. }\end{array}$ \\
\hline 2 & Oxygen/DROS & $\begin{array}{l}\mathrm{O}_{2} \text { confined to Complex IV and no role in } \\
\text { phosphorylation; DROS are toxic wastes }\end{array}$ & $\begin{array}{l}\mathrm{O}_{2} \text { involved at Complexes I-IV; direct } \\
\text { role in phosphorylation; DROS are } \\
\text { quintessential }\end{array}$ \\
\hline 3 & $\begin{array}{l}\text { Protons' or } \\
\text { ions' fluxes }\end{array}$ & Serve to build up TMP in steady-state & Serve to neutralize TMP in steady-state \\
\hline 4 & $A D P$ & $\begin{array}{l}\text { Confined to one site on } \beta \text {-monomer of } \\
\text { Comp. } V\end{array}$ & $\begin{array}{l}\text { Binds at multiple sites on Comp. I- IV; } \\
\text { binds at two sites on } \beta \text {-monomer of } \\
\text { Comp. V }\end{array}$ \\
\hline 5 & Comp. V & $\begin{array}{l}\text { ATP-synthase, which taps the TMP by rotary } \\
\text { or torsional modalities }\end{array}$ & $\begin{array}{l}\text { Chemostat (cation-pore), neutralizing } \\
\text { negative charges within matrix }\end{array}$ \\
\hline 6 & Comp. I & $\begin{array}{l}\text { NADH dehyrogenase, CoQ reductase, } \\
\text { Proton/ion translocase }\end{array}$ & $\begin{array}{l}\text { ATP-synthase (ADP-binder \& DROS } \\
\text { generator/stabilizer) from NADH }\end{array}$ \\
\hline
\end{tabular}




\begin{tabular}{|c|c|c|c|}
\hline 7 & Comp. II & Succinate dehydrogenase, CoQ reductase & $\begin{array}{l}\text { ATP-synthase (ADP-binder \& DROS } \\
\text { generator/stabilizer) from succinate }\end{array}$ \\
\hline 8 & Comp. III & $\begin{array}{l}\text { CoQ dehydrogenase, Cyt. } c \text { reductase, } \\
\text { Proton/ion translocase }\end{array}$ & $\begin{array}{l}\text { ATP-synthase (ADP-binder \& DROS } \\
\text { generator/stabilizer) from reduced CoQ } \\
\text { and DROS }\end{array}$ \\
\hline 9 & Comp. IV & $\begin{array}{l}\text { Cyt. } c \text { - oxygen oxidoreductase, Proton/ion } \\
\text { translocase }\end{array}$ & $\begin{array}{l}\text { ATP-synthase (ADP-binder \& DROS } \\
\text { generator/stabilizer) from reduced } \\
\text { CoQ, reduced Cyt. } c \text { and DROS }\end{array}$ \\
\hline 10 & Cyt. c & IMS-phase electron relay & $\begin{array}{l}\text { Aqueous-phase 1e sink and redox } \\
\text { buffer/capacitor }\end{array}$ \\
\hline 11 & CoQ & Membrane-phase 2 e relay & $\begin{array}{l}\text { Membrane-phase } 1 \mathrm{e} / 2 \mathrm{e} \text { sink or redox } \\
\text { buffer }\end{array}$ \\
\hline 12 & $\begin{array}{l}\text { Mitochondrial } \\
\text { membrane(s) }\end{array}$ & $\begin{array}{l}\text { Intelligent regulation of components' } \\
\text { steady-state dynamics for efficient TMP } \\
\text { harnessing }\end{array}$ & $\begin{array}{l}\text { Cardiolipin limits superoxide flux; highly } \\
\text { packed proteins \& CoQ use DROS and } \\
\text { limit proton flux }\end{array}$ \\
\hline
\end{tabular}

\$ From [41]; \# From the energies required for the heterolysis of water [20] and proton translocation [35]; the murburn model of mOxPhos does not negate some of the charted roles of the bold protein entries 5-10 and the roles listed in the table are the added functionality.

1. Overall reaction scheme \& equations - The Jagendorf's [42] and Racker's [43] experiments were erroneously taken as support for Mitchellian proposal of a trans-membrane proton/electrical gradient serving as energetic drive for ADP-phosphorylation. This was adequately explained and duly corrected by Manoj [12]. Several key aspects were overlooked regarding protons' roles in mitochondrial physiology- (i) mitochondria are practically aprotic, rendering proton pumping unfeasible, (ii) NADH oxidation needs extraneous protons and therefore, the mitochondria cannot function in a closed-cyclic manner as the Mitchellian proposal seeks, (iii) at physiological pH, esterification of ADP and Pi needs protons (because $\mathrm{pK}_{\mathrm{a}}$ of ADP and Pi fall around the same $\mathrm{pH}$ ranges) and this fact would enable equilibrium driven ATP-synthesis by Complex V in reductionist/physiological systems, and (iv) protons contribute an overwhelmingly large $\Delta_{\mathrm{r}} G^{\prime \mathrm{o}}$ aq value term of $-452 \mathrm{~kJ} / \mathrm{mol}$, rendering the equilibrium-driven ATP-synthesis reaction highly favourable [20]. However, the equilibriumdriven ATP synthesis by Complex V has no physiological relevance, as neither a high pH gradient nor a steady TMP can lead to ATP synthesis within mitochondria in its normal physiological setup [12]. Hence, there is no realistic concept of "coupling" of NADH oxidation with ATP synthesis in the CRAS-TITAS models, and the proposed coupling modality is thermodynamically unviable (as shown in point 1 of Table 1). Murburn hypothesis, on the other hand, is a simple bi-molecular reaction scheme that provides sound chemico-physical logic for DROS-driven ATP synthesis, TMP generation (as a consequence of negatively charged DROS/CoQ ${ }^{*-}$ within mitochondria), thermogenesis (DROS reacting among themselves) and homeostasis (water's turgor movement outward, owing to colligative properties) $[18,19,20]$. Further, while the murburn model presents tangible/tenable 
explanations for the outcomes observed with various additives/toxicants (uncouplers like diphenolics, rotenone, retinoids, cyanide, etc.) [18,19,20-22] and supports a spontaneously evolvable powering routine $[4,5,17]$, the CRAS-TITAS model fails in these criteria. A recent manuscript [19] tabulates 30 distinct reasons why the oxygen or DROS-centric murburn model is favourable over the proton or TMP-centric CRAS-TITAS model. I wonder how anyone can overlook such a comprehensive volume of criticism of CRAS-TITAS and ignore the murburn model, which is like an elephant in the room!

2. Oxygen - In the CRAS-TITAS model, oxygen has practically no real role, and binds only to Complex IV and is not physiologically associated with any other proteins/complexes. This counters common sense and available evidence, as most mitochondrial proteins are known to interact with oxygen, producing diffusible reactive oxygen species (DROS) [18]. In the murburn model, oxygen is converted to DROS, which drive ATP generation and hence, oxygen has a direct role in energy metabolism. Also, DROS are routinely produced in mitochondria and it is hard to imagine that oxygen stays bound to Complex IV to receive four electrons and four protons, only to make two molecules of water. DROS production cannot merely be an aberration of physiology, as these species are small ( 1-2 $\AA$ ) and have a conservative mobility of $10^{2} \AA / \mu \mathrm{s}$, when biological electron transfers are observed across 5$30 \AA$ Å, within millisecond to microsecond timescales [12,24]. Therefore, the physiological functioning of deterministic electron transport chains is questionable. On the other hand, increasing the supply of $\mathrm{NADH} / \mathrm{succinate} / \mathrm{ADP} / \mathrm{Pi} / \mathrm{O}_{2}$ to mitochondria is directly correlated to increase of DROS within milieu [44]; and DROS is directly correlated to TMP and ATPsynthesis [45]. Further, from item 1 of Table 1, it can be seen that the DROS-centric murburn model equation of mitochondrial ATP synthesis efficiently accounts for the high efficiency reported for mOxPhos, whereas the CRAS is unviable. DROS can drive phosphoanhydride formation in aprotic environments, and we have amply demonstrated the proof of concept with in vitro [18,22] experiments and literature also supports this for the in vivo [46] perspective.

3. Protons/other ions - The CRAS-TITAS proposal not only restricts oxygen's free movement, it deterministically prescribes the same fate for protons/other ions, which are considered to be specifically used only at certain loci within the reaction system. It is elementary deduction that if a negative potential (as is observed in physiological steady state) must exist across the mitochondrial membrane, the scenario would entail that there is either a nett surplus of negative charges in the inside phase or a nett surplus positive charges on the 
outside phase (relative to each other). Both the CRAS and TITAS systems rely on cyclic ionic differentials/translocations to account for TMP. However, while there is some simplistic appeal of the untenable CRAS proposal (which says that when matrix protons are pumped out, it increases positive charge within IMS), the TITAS model only complicates with added whorls and does not offer any explanation for TMP when advocating for translocation of ions with their counter-ions. (This is what happens with false proposals: try to set one side straight by introducing arbitrary/unrealistic weights and terms at one end, and the system does not add up at the other end!) In contrast, the murburn model does not restrict proton movement across membranes and is an "open and continuously fed pot" model with respect to protons/ions (Figure 1). Charge separation at Complexes I through IV results efficiently due to the multitudes of 1e redox centers and copious amounts of oxygen. Owing to the highly packed inner membrane of mitochondria, the matrix becomes transiently proton/cation deficient (by the facts that NADH gives two electrons but only one proton, oxygen can get reduced to give negatively charged DROS like superoxide, CoQ can get reduced to give a negatively charged semiquinone, etc.), which is continuously neutralized by the incoming cytoplasmic protons. Since proton movement across membranes takes millisecond timescales [47], this is essentially one of the limiting factors for mOxPhos reactions, which is overcome by having Complex V (an ion-equilibrium facilitating agent) with an 'operable' cationic pore. The formation of a lower number of products + water (when compared to the number of reactant molecules) provides the homeostatic drive for water efflux from matrix (via porins) $[19,20]$.

4. ADP - In CRAS-TITAS model, ADP needs to bind only to Comp. V, and does not interact with other complexes. Manoj and his coworkers have shown using in silico techniques that eukaryotic and prokaryotic respiratory complexes (I-V) possess ADP binding sites (on the subtending, matrix-ward regions of the complexes) [18]. This fact is also supported by experimental research published from highly reputed labs that report ADP-binding for the mitochondrial Complexes I-IV [48-51]. While Walker's phosphate binding motifs would be anticipated for ATP-binding, Manoj's group has amply shown that the respiratory proteins have evolved for adenosine binding [18]. These binding motifs are not false-positives, as Manoj's group has cross-verified that controls of nicotinamide adenine dinucleotides (oxidized or reduced NAD/NADP) do not proffer any effective binding on the membrane proteins at the same sites. 
5. Comp V - Very importantly, the CRAS/TITAS proposal weaves P-O bonds through a macroscopic and delocalized TMP tapping, by a fantastic 'proton-motive force' or/and 'electro-mechanical stunt' of Complex V, unheard of in any other fields of chemico-physics. Stretching all figments of imagination, such a facet could perhaps have been enabled if Comp. V had any ferromagnetic component and if the TMP was oscillating (enabling the proteins to change conformation, based on voltage cues). However, the latter requirement would necessitate a synchronized functioning of the proton pumps of Complexes I, III \& IV! (This would be analogous to how the various valves and chambers of a mammalian heart work in concert for pumping blood to and from various loci!) But such TMP tapping components and networked facets are clearly lacking in the mitochondrial machinery. Comp. $\mathrm{V}$ is a known ATPase, and it cannot work as a synthase unless equilibrium conditions favour so. Since physiological conditions have almost millimolar levels of ATP, Complex V driven ATP synthesis is ruled out, as it can only give a maximal of nanomolar levels of ATP, given the low $\mathrm{K}_{\mathrm{eq}}$ for this reaction [19]. Moreover, in silico analyses showed that the $\beta$ monomers of Complex V contains two ADP binding sites [18], and this is also supported by earlier published experimental research [52]. Neither the CRAS nor TITAS models accommodate or account for this fact. The multiple ADP-binding sites within a $\beta$-monomer is quite reasonable within the murburn paradigm, within which, Complex $\mathrm{V}$ does not need to possess any 'rotary/torsional/circular' facets and need not tap any TMP either [19]. Under the murburn purview, the simplest explanation for the conserved DELSEED loops located on the $\beta$ monomers is that they serve to bring in the cationic charges $/ \mathrm{H}^{+}$ions through the c-ring pore. Clearly, our explanation is supported by the binding of oligomycin to the c-subunit of $F_{o}$ (due to which the module derives its conventional name!) [19].

6-9. Comp I-IV - The purported membrane-laden proteins of the erstwhile electron transport chain (ETC) of CRAS-TITAS are also supposed to serve as proton/ion translocators across the IPLM. There is hardly any direct and irrefutable evidence for such proposals. For example- The proton-pump promulgator Mitchell and the seasoned researcher Nalecz questioned if Complexes IV and III (respectively) were proton pumps [53,54]! There exists hardly any consensus on the mechanism, identity $\left(\mathrm{H}^{+}\right.$or $\mathrm{Na}^{+}$, for example) or stoichiometry (number of protons per electron) of proton/ion translocation in various complexes amongst the mOxPhos researchers [23]. Therefore, the non-feasibility of proton-pumps that Manoj pointed out $[11,12]$ is supported by the lack of experimental evidence and consensus. Further, in Complex I, it is inconceivable how electron transfers (occurring at microsecond timescales 
within the long matrix-subtended arm) could be synchronized with proton movements across the membrane-embedded foot (which occurs at millisecond timescales) [12]. Several redox centers in the Complexes (for example: two non-route Fe-S centers in Complex I, the transmembrane heme in Complex II, etc.) seem to have no roles whatsoever [12]! Many redox centers within the respiratory proteins are easily solvent accessible and also present in unfavourable redox gradient sequences, refuting the concept of a tightly wired and serial ETC concept [12]. The matrix-ward distended portion of Complex III has apparently no roles whatsoever! These are just a few of the examples of the structure-function correlation issues that Manoj had unveiled regarding the ETC-CRAS concept [12,19]. In toto, the ETC arrangement neither makes any physiological purpose (given that proton-cycling is nonviable in mitochondria, as all these proteins exist just to transfer electrons and make water?) nor affords kinetic viability (owing to serial/sequential connectivity). In the murburn purview, the membrane-laden proteins are seen as parallel-networked murzymes [11,22] that bind ADP and present DROS effectively to bring about ATP synthesis. This model is supported by the evidence that Complexes I through IV have ADP-binding sites and are known to bind ADP [18]; they also have multitudes of 1e redox active centers that could be accessed by oxygen/DROS and all these proteins are also known to generate DROS independently [55-58]. In particular, while the CRAS-TITAS explanations fail to afford adequate structure-function correlations [12], the murburn model presents very convincing roles, particularly for Complexes I and III [19,23].

10. Cyt. $c$ - According to CRAS-TITAS model, cytochrome $c$ is a specific ET relay agent which facilitates electron transfer between the disconnected complexes III and IV, through redox chemistry of heme iron, which cycles between $2^{+}$and $3^{+}$states and aid in IMS-phase electron relay. In my comprehensive analysis of cytochrome $c$ from diverse organisms (bacteria, plants and animals), I did not find any strict conservation of surface aminoacids which are touted to be critical for protein-protein complexations between cytochrome $c$ and its redox partners (subunits of complex III and IV) [30]. Plus, mutants of cytochrome $c$ and its redox partners (of critical aminoacids believed to be involved in protein-protein interactions) did not significantly abrogate electron transfers and therefore, evidence indicates that it most probably serves as electron buffer within the stochastic murburn reaction equilibriums [30]. The evolutionary link between cytochrome $c$ leaching and cellular apoptosis [59] is explained by murburn model as a result of DROS-burden leading from mitochondrial membrane rupture (which is deleterious to the whole organism). 
11. CoQ - Both Complexes I and II reduce ubiquinone and this mobile element is known to transport electrons from these complexes to Complex III [38-41]. However, Manoj's group has argued that ubiquinone is a bulky and long hydrophobic entity, which cannot possibly move around freely in the essentially dimensionally constricted lipid environment of the mitochondrial membrane [23]. This take is also supported by earlier/known values of diffusion constants of quinones in biological membranes showing that the lateral motility of quinines would be rate-limiting [60-63]. If motility was the intended purpose, $\mathrm{CoQ}_{6}$ should have been more preponderant than $\mathrm{CoQ}_{10}$, which is not the case. The murburn purview justifies these realities by attributing CoQ with a $1 \mathrm{e}$ or $2 \mathrm{e}$ redox pit status within the membrane [23]. Further, the thermodynamic analysis of semiquinone and its interactions with oxygen also provide strong support for the murburn purview [20].

12. Mitochondrial membranes - In the CRAS-TITAS purview, the inner membrane should serve 'intelligent' functions, not allowing free diffusion of small molecule/ions, and must network the various protein complexes and enable the smart/miraculous tapping of TMP. Further, the CRAS-TITAS view fails to explain the preponderance of cardiolipin at one hand and also seeks that the outer membrane must also regulate the ions and small molecules. The above perceptions are impossible to attain in physiology, as the IMS or periplasm is expected to be in equilibrium with the external ambiance. The DROS-centric murburn model explains cardiolipin as a means to lower trans-membrane flux of superoxide and does not require the outer membrane or inner membrane to be restrictive.

To conclude, I affirm that the CRAS-TITAS model is untenable from energetics, kinetics, mechanistic and probabilistic perspectives. Therefore, caution must be exercised against interpretation of experimental data using such defective ideas. A reaction is the sum of its components. The CRAS-TITAS mechanism appears untenable with respect to the nature of its components. The advantages of seeing DROS as useful agents far outweigh the aesthetically driven pitfall of neglecting them as toxic/undesirable waste products. As demonstrated earlier for CYP-mediated drug metabolism [10] and for mOxPhos [19], only the DROS-based murburn model offers valid explanations and its advocate also projects experiments to further ratify the new ideas $[10,19]$. Most importantly, the murburn model of mOxPhos permits a spontaneously formable and naturally evolvable working system, with each protein component capable of independent functioning [5,13,17]. In stark contrast, the CRAS/TITAS model needs all the elements of the purported ETC and the highly sophisticated Complex V as well as the selective membranes to work as a highly integrated 
system. Even then, it does not justify mitochondrial physiology! While the CRAS-TITAS system is a highly fastidious and practically miraculous mechanism unheard of elsewhere, the murburn model entails a bunch of reaction equilibriums that have optimized and evolved over time and space. Moreover, the new model also justifies the formation of respirasomes like $\mathrm{I}(\mathrm{III})_{2} \mathrm{IV}$, as a logic for effective utilization of DROS [18]. The fact that both prokaryotic [64] and eukaryotic [65] single-celled organisms that are defunct or deficient in Complex V survive/grow is support for the secondary nature of Complex $\mathrm{V}$ in physiological ATP synthesis. Further, the recent isolation of a cnidarian parasite with mitochondria devoid of Complexes I, III and IV (the purported proton pumps of CRAS-proposal) [66], render 'ETCbased CRAS' redundant. Such findings are compatible within the murburn purview, which can support peroxidative phosphorylation starting from Complex II, as originally reported by Galina Mironova [67]. Most crucially, the murburn model justifies the pioneers Mildred Cohn's [68] and Kathleen Mailer's [46] observations noted upon ${ }^{18} \mathrm{O}-$-label $/ \mathrm{O}_{2}{ }^{{ }^{*}-}$ provisions (respectively) to respiring mitochondria, while the CRAS model cannot [20]. It is high time to think beyond Complex V-mediated physiological mOxPhos, as it is a proven ATPase that enables organelle homeostasis. I hope that the community would not deprive the world the benefits of seeing DROS under a new light and also mind itself from the guilt conscience of teaching CRAS as an explanation for mOxPhos to yet another generation of young minds.

\section{References}

[1] P.J. Silva, Chemiosmotic misunderstandings, Biophysical Chemistry, 264 (2020), 106424. doi:10.1016/j.bpc.2020.106424

[2] S. Nath, Molecular-level understanding of biological energy coupling and transduction: Response to "Chemiosmotic misunderstandings", Biophysical Chemistry, $268 \quad$ (2020), 106496. doi:10.1016/j.bpc.2020.106496

[3] K.M. Manoj, Refutation of the cation-centric torsional ATP synthesis model and advocating murburn scheme for mitochondrial oxidative phosphorylation, Biophysical Chemistry, 257 (2020), 106278. doi:10.1016/j.bpc.2019.106278

[4] K.M. Manoj, Murburn concept: a paradigm shift in cellular metabolism and physiology, Biomolecular Concepts, 11(2020), 7-22. doi:10.1515/bmc-2020-0002

[5] K.M. Manoj, Rebutting Pedro J. Silva's article in Biophysical Chemistry supporting Mitchell-Boyer's ideas on bioenergetics and advocating murburn concept as a viable explanation for aerobic respiration and oxygenic photosynthesis. OSF Preprints, (2020). https://doi.org/10.31219/osf.io/w97af

[6] K.M. Manoj, V. Soman, V.D. Jacob, et al., Atypical profiles and modulations of heme-enzymes catalyzed outcomes by low amounts of diverse additives suggest diffusible radicals' obligatory involvement in reactions, Biochimie, 125 (2016), 108128. doi:10.1016/j.biochi.2016.03.003.

[7] A. Venkatachalam, A. Parashar, K.M. Manoj, Functioning of drug-metabolizing microsomal cytochrome P450s: In silico probing of proteins suggest that the distal heme 'active site' pocket plays a relatively 'passive role' in some enzyme-substrate interactions, In Silico Pharmacology, 4 (2016), 2. doi:10.1186/s40203-016-00167 
[8] K.M. Manoj, A. Venkatachalam, A. Parashar, Metabolism of xenobiotics by cytochrome P450: novel insights into the thermodynamics, kinetics and roles of redox proteins and diffusible reactive species, Drug Metabolism Reviews, 48 (2016), 41-42. doi: doi:10.3389\%2Ffphar.2016.00161

[9] K.M. Manoj, S.K. Gade, A. Venkatachalam, et al., Electron transfer amongst flavo-and hemo-proteins: diffusible species effect the relay processes, not protein-protein binding, RSC Advances, 6 (2016), 24121. doi:10.1039/C5RA26122H

[10] K.M. Manoj, A. Parashar, S.K. Gade, et al., Functioning of microsomal cytochrome P450s: Murburn concept explains the metabolism of xenobiotics in hepatocytes, Frontiers in Pharmacology, 7 (2016), 161. doi:10.3389/fphar.2016.00161

[11] K.M. Manoj, Debunking chemiosmosis and proposing murburn concept as the operative principle for cellular respiration, Biomedical Reviews, 28 (2018), 31-48. doi:10.14748/bmr.v28.4450

[12] K.M. Manoj, Aerobic Respiration: criticism of the proton-centric explanation involving rotary adenosine triphosphate synthesis, chemiosmosis principle, proton pumps and electron transport chain, Biochemistry Insights, 11 (2018), 1178626418818442. doi:10.1177\%2F1178626418818442

[13] K.M. Manoj, The ubiquitous biochemical logic of murburn concept, Biomedical Reviews, 29 (2018), 8997. doi:10.14748/bmr.v29.5854

[14] K.M. Manoj, D.A. Gideon, V.D. Jacob, Murburn scheme for mitochondrial thermogenesis, Biomedical Reviews, 29 (2018), 73-82. doi:10.14748/bmr.v29.5852

[15] A. Parashar, D.A. Gideon, K.M. Manoj, Murburn concept: A molecular explanation for hormetic and idiosyncratic dose responses, Dose Response, 16 (2018), 1. doi:10.1177/1559325818774421

[16] D.A. Gideon, V.D. Jacob, K.M. Manoj, 2020: murburn concept heralds a new era in cellular bioenergetics, Biomedical Reviews, 30 (2019), 89-98. doi:10.14748/bmr.v30.6390

[17] K.M. Manoj, Torday's prognosis for aging and mortality: more evolution and better life! Biomedical Reviews, 30 (2019), 23-24. doi:10.14748/bmr.v30.6384

[18] K.M. Manoj, A. Parashar, V. David Jacob, S. Ramasamy, Aerobic respiration: proof of concept for the oxygen-centric murburn perspective, Journal of Biomolecular Structure and Dynamics, 37 (2019), 4542-4556. doi:10.1080/07391102.2018.1552896

[19] K.M. Manoj, V. Soman, V.D. Jacob, et al., Chemiosmotic and murburn explanations for aerobic respiration: predictive capabilities, structure-function correlations and chemico-physical logic, Archives of Biochemistry and Biophysics, 676 (2019), 108128. doi: 10.1016/j.abb.2019.108128

[20] K.M. Manoj, N.M. Bazhin, Murburn precepts of aerobic respiration and homeostasis. OSF Preprints, (2019). doi:10.31219/osf.io/hx4p9

[21] K.M. Manoj, V. Soman, Classical and murburn explanations for acute toxicity of cyanide in aerobic respiration: A personal perspective, Toxicology, 432 (2020), 152369. doi:10.1016/j.abb.2019.108128

[22] K.M. Manoj, S. Ramasamy, A. Parashar, et al. Acute toxicity of cyanide in aerobic respiration: Theoretical and experimental support for murburn explanation, Biomolecular Concepts, 11 (2020), 32-56. doi:10.1515/bmc2020-0004

[23] K.M. Manoj, D.A. Gideon, A. Parashar, What is the role of lipid membrane-embedded quinones in mitochondria and chloroplasts? Chemiosmotic Q-cycle versus murburn reaction perspective, Cell Biochemistry and Biophysics, (2020) 1-8. doi:10.1007/s12013-020-00945-y

[24] D.A. Gideon, V. Nirusimhan, K.M. Manoj, Are plastocyanin and ferredoxin specific electron carriers or generic redox capacitors? Classical and murburn perspectives on two photosynthetic proteins, Journal of Biomolecular Structure and Dynamics. doi:10.1080/07391102.2020.1835715

[25] K.M. Manoj, Critical analysis of some assumptions and observations on photolytic oxygenesis by plant cells, OSF Preprints, (2020). doi: 10.31219/osf.io/y62j5

[26] K.M. Manoj, D.A. Gideon, V.D. Jacob, et al., Is Z-scheme a tenable explanation for the light reaction of oxygenic photosynthesis? OSF Preprints, (2020). doi: 10.31219/osf.io/v6tdf

[27] K.M. Manoj, D.A. Gideon, A. Parashar, et al., Role of thylakoid membranes in oxygenic photosynthesis: A comparative perspective using murburn concept. OSF Preprints, (2020). doi:10.31219/osf.io/8p2sx 
[28] K.M. Manoj, N.M. Bazhin, A. Parashar, et al., Murburn precepts for the light reaction of oxygenic photosynthesis. OSF Preprints, (2020). doi: 10.31219/osf.io/95brg

[29] K.M. Manoj, A. Manekkathodi, Light's interaction with pigments in chloroplasts: The murburn perspective. OSF Preprints, (2020). doi: 10.31219/osf.io/wx4gv

[30] K.M. Manoj, D.A. Gideon, Roles of cytochromes c and b5 in mitochondria and microsomes: Classical and murburn perspectives. OSF Preprints, (2020). doi:10.31219/osf.io/8a6ej

[31] K.M. Manoj, A. Parashar, Murburn precepts for cytochrome P450 mediated drug/xenobiotic metabolism, OSF Preprints, (2020). doi:10.31219/osf.io/97ckh

[32] K.M. Manoj, H. Tamagawa, A critical appraisal on cellular homeostasis, transduction of environmental stimuli and the elicitation of electrophysiological responses, OSF Preprints, (2020). doi:10.31219/osf.io/e2ynk

[33] P.D. Boyer, Phosphohistidine, Science, 141 (1963), 1147-1153. doi: 10.1126/science.141.3586.1147

[34] P.D. Boyer, The ATPsynthase- A splendid molecular machine. Annual Review of Biochemistry, 66 (1997), 717-749. doi: 10.1146/annurev.biochem.66.1.717

[35] A.L. Lehninger, D.L. Nelson \& M. Cox, Lehninger: Principles of Biochemistry (Chapter 19, section titled ATP is stabilized relative to ADP on surface of F1 page 709, left column, paragraph 3) London, England: Palgrave Macmillan; 2004.

[36] S. Gupte, E.S. Wu, L. Hoechli, et al., Relationship between lateral diffusion, collision frequency, and electron transfer of mitochondrial inner membrane oxidation-reduction components, Proceedings of the National Academy of Sciences of the United States of America, 81 (1984), 2606-2610. doi:10.1073/pnas.81.9.2606

[37] K. Schwerzmann, L.M. Cruz-Orive, R. Eggman, et al., Molecular architecture of the inner membrane of mitochondria from rat liver: a combined biochemical and stereological study, Journal of Cell Biology, 102 (1986), 97-103. doi:10.1083/jcb.102.1.97

[38] B. Alberts, A. Johnson, J. Lewis, et al., Molecular Biology of the Cell 4th edn. (Garland Science, 2002).

[39] J. M. Berg, J. L. Tymoczko, L. Stryer, Biochemistry 5th edn. (W H Freeman, 2002).

[40]. H.F. Lodish, Molecular Cell Biology 6th edn. W.H. Freeman and Company, 2008.

[41] D. Voet, In Voet D., Voet JG (Eds.) Biochemistry 4th edn, 2011. John Wiley \& Sons, Inc.

[42] A.T. Jagendorf, E. Uribe, ATP formation caused by acid-base transition of spinach chloroplasts. Proceedings of the National Academy of Sciences of the United States of America, 55 (1966), 170-177. doi:10.1073\%2Fpnas.55.1.170

[43] E. Racker, W. Stoeckenius, Reconstitution of purple membrane vesicles catalyzing light-driven proton uptake and adenosine triphosphate formation, Journal of Biological Chemistry, 249 (1974), 662-663.

[44] M.P. Murphy, How mitochondria produce reactive oxygen species, Biochemical Journal, 417 (2009), 1-13. doi:10.1042/BJ20081386

[45] D.G. Nicholls, Mitochondrial membrane potential and aging, Aging Cell, 3 (2004), 35-40. doi:10.1111/j.1474-9728.2003.00079.x

[46] K. Mailer, Superoxide radical as electron donor for oxidative phosphorylation of ADP, Biochemical and Biophysical Research Communications, 170 (1990), 59-64. doi:10.1016/0006-291x(90)91240-s

[47] C.M. Biegel, J.M. Gould, Kinetics of hydrogen ion diffusion across phospholipid vesicle membranes, Biochemistry, 20 (1981), 3474-3479. doi:10.1021/bi00515a026

[48] T.V. Zharova, A.D. Vinogradov, A competitive inhibition of the mitochondrial NADH-ubiquinone oxidoreductase (Complex I) by ADP-ribose, Biochimica et Biophysica Acta, 1320 (1997), 256-264. doi:10.1016/S0005-2728(97)00029-7

[49] C. Affourtit, K. Krab, G.R. Leach, et al., New insights into the regulation of plant succinate dehydrogenase: On the role of protonmotive force, Journal of Biological Chemistry, 276 (2001), 32567-32574. doi:10.1074/jbc.m103111200

[50] J. Napiwotzki, K. Shinzawa-Itoh, S. Yoshikawa, B. Kadenbach, ATP and ADP bind to cytochrome c oxidase and regulate its activity, Biological Chemistry, 378 (1997), 1013-1022. doi:10.1515/bchm.1997.378.9.1013 
[51] S. Arnold, B. Kadenbach, Cell respiration is controlled by ATP, an allosteric inhibitor of cytochrome- c oxidase, European Journal of Biochemistry, 249 (1997), 350-354. doi:10.1111/j.1432-1033.1997.t01-1-00350.x

[52] D. Khananshvili, Z. Gromet-Elhanan, Demonstration of two binding sites for ADP on the isolated $\beta$ - subunit of the Rhodospirillum rubrum R1F0F1- ATP synthase, FEBS letters, 178 (1984), 10-14. doi:10.1016/0014-5793(84)81229-6

[53] M.J. Nałęcz, Is there sufficient experimental evidence to consider the mitochondrial cytochrome bc 1 complex a proton pump? Probably no, Journal of Bioenergetics and Biomembranes, 18 (1986), 21-38. doi:10.1007/BF00743610

[54] J. Moyle, P. Mitchell, Cytochrome c oxidase is not a proton pump, FEBS Letters, 88 (1978), $268-272$. doi:10.1016/0014-5793(78)80190-2

[55] V.G. Grivennikova, A.D. Vinogradov, Generation of superoxide by the mitochondrial Complex I, Biochimica et Biophysica Acta, 1757 (2006), 553-561. doi:10.1016/j.bbabio.2006.03.013

[56] S. Drose, Differential effects of Complex II on mitochondrial ROS production and their relation to cardioprotective pre-and postconditioning, Biochimica et Biophysica Acta (BBA) - Bioenergetics, 1827 (2013), 578-587. doi:10.1016/j.bbabio.2013.01.004

[57] L. Bleier, S. Dröse, Superoxide generation by Complex III: From mechanistic rationales to functional consequences, Biochimica et Biophysica Acta (BBA) - Bioenergetics, 1827 (2013), 1320-1331. doi:10.1016/j.bbabio.2012.12.002

[58] M.Y. Ksenzenko, T. Vygodina, V. Berka, et al., Cytochrome oxidase-catalyzed superoxide generation from hydrogen peroxide, FEBS Letters, 297 (1992), 63-66. doi:10.1016/0014-5793(92)80328-e

[59] Y. Aramaki, S. Takano, S. Tsuchiya, Cationic liposomes induce macrophage apoptosis through mitochondrial pathway, Archives of Biochemistry and Biophysics, 392 (2001), 245-250. doi:10.1006/abbi.2001.2458

[60] H. Kirchhoff, Diffusion of molecules and macromolecules in thylakoid membranes, Biochimica et Biophysica Acta (BBA)- Bioenergetics, 1837 (2014), 495-502. doi:10.1016/j.bbabio.2013.11.003

[61] M. Blackwell, C. Gibas, S. Gygax, et al., The plastoquinone diffusion coefficient in chloroplasts and its mechanistic implications, Biochimica et Biophysica Acta (BBA)-Bioenergetics, 1183 (1994), 533-543.

[62] S. Gupte, E.S. Wu, L. Hoechli, et al., Relationship between lateral diffusion, collision frequency, and electron transfer of mitochondrial inner membrane oxidation-reduction components, Proceedings of the National Academy of Sciences of the United States of America, 81 (1984), 2606-2610. doi:10.1073/pnas.81.9.2606

[63] B. Chazotte, C. Hackenbrock, Lateral diffusion as a rate-limiting step in ubiquinone-mediated mitochondrial electron transport, Journal of Biological Chemistry, 264 (1989), 4978-4985.

[64] D.J. Klionsky, W.S.A. Brusilow, R.D. Simoni, In vivo evidence for the role of the epsilon subunit as an inhibitor of the proton-translocating ATPase of Escherichia coli, Journal of Bacteriology, 160 (1984), 10551060.

[65] A. Sturm, et al., Mitochondrial ATP synthase is dispensable in blood-stage Plasmodium berghei rodent malaria but essential in the mosquito phase, Proceedings of the National Academy of Sciences of the United States of America, 112 (2015), 10216-10223.

[66] D. Yahalomi, et al., A cnidarian parasite of salmon (Myxozoa: Henneguya) lacks a mitochondrial genome. Proceedings of the National Academy of Sciences of the United States of America, 117 (2020), 5358-5363. doi:10.1073\%2Fpnas.1423959112

[67] G.D. Mironova, Metmyoglobin and peroxide compounds in mitochondria, In Mitochondria. Structure and functions in norm and pathology. pp 169-173. Nauka, Moscow (1971).

[68] M. Cohn, A study of oxidative phosphorylation with O18-labeled inorganic phosphate, Journal of Biological Chemistry, 201 (1953), 735-750. 